\title{
Idiopathic granulomatous hepatitis and abdominal pain
}

\author{
C. D. SHEE \\ B. Creamer \\ M.B., M.R.C.P. \\ M.D., F.R.C.P. \\ The Gastrointestinal Unit, Rayne Institute, St Thomas' Hospital, London SE1 7EH
}

\begin{abstract}
Summary
Granulomatous hepatitis may present with abdominal pain. Four patients are described who had longstanding severe abdominal pain associated with this condition.

Introduction

'Granulomatous hepatitis' is not a disease but a pathological reaction that may be elicited by a large number of stimuli. After careful investigation an underlying cause is often found (Neville, Piyasena and James, 1975).
\end{abstract}

In the last 3 years, 4 women with idiopathic granulomatous hepatitis presented with similar rightsided abdominal pain. During intensive investigation for this pain, liver biopsies were performed; all of which showed multiple non-caseating granulomata.

\section{Patients and results}

\section{Patient 1}

A 72-year-old presented with a 3-year history of right-sided and central abdominal pain. This was worse at night, after food, and was sometimes associated with vomiting. Intensive investigation, including barium meal and enema, cholecystogram, intravenous pyelogram (IVP) and endoscopic retrograde cholangiopancreatogram (ERCP) did not reveal a cause. Her liver function tests were normal, but ultrasonography twice suggested an hepatic mass. At laparotomy no abnormality was found and the liver was biopsied. Two years later (1979) she remains well but the pain persists, being partially eased by simple analgesia.

\section{Patient 2}

A 38-year-old Jamaican was investigated for abdominal pain which had been present for 2 years. The pain was maximal in the right hypochondrium, occasionally causing her to roll in agony or to vomit. She appeared unwell and had lost weight. Her ESR was 62 in the 1st hr (Westergren), alkaline phosphatase $83 \mathrm{KAu}$. (normal 4-13), serum aspartate transaminase (SGOT) 115 i.u./1 (25-65) and $\gamma$-glutamyl transpeptidase $(\gamma-G T) 86 \mathrm{u} . / 1(0-18)$. A liver scan, barium meal, cholecystogram, IVP and ERCP were normal. Hepatic metastases were suspected and at laparoscopy diffuse white mottling

Requests for reprints: C. D. Shee, Department of Medicine, St Thomas's Hospital, London, S.E.1. was seen on the liver, which was biopsied; no othe 5 abnormality was present. Because of systemic upset she was treated with prednisone, $30 \mathrm{mg} /$ day andw improved dramatically. The liver function tests an 8 ESR returned to normal but on maintenance treat ment with $7 \mathrm{mg}$ /day mild pain has returned.

\section{Patient 3}

A 79-year-old presented with a 6-month histores of right hypochondrial pain and weight lossi The pain was aggravated by movement or food and sometimes radiated to her back and right shouldero Tender hepatomegaly was present but liver functiontests were normal apart from a $\gamma$-GT of $69 \mathrm{u} . / 13$ Gastroscopy and barium enema were normal but an ultrasound examination and Tc-sulphur-colloide scan were suggestive of hepatic metastases. laparoscopy biopsies were taken from the liver whitet appeared enlarged but otherwise normal. The pâp settled spontaneously and she has remained well fong 2 years.

\section{Patient 4}

A 54-year-old had a past history of chole $\overrightarrow{7}$ cystectomy and removal of a chromophobe adenoma. For 2 years she had suffered from severe intermittent right-sided abdominal pain. Her alkae. line phosphatase was $22 \mathrm{KAu}$., SGOT 113 i.u. and $\gamma$-GT $64 \mathrm{u}$./1. ERCP was normal and there was diminished hepatic uptake on a Tc-sulphur-colloid scan. A percutaneous liver biopsy was performed. She now (1979) gets less frequent pain but is diso tressed during the attacks.

\section{Investigations}

The following investigations were normal in ever patient: full blood count, bilirubin, antimitochon drial antibodies, tuberculin skin test, chest X-ray anst gastroscopy. The liver biopsies all showed multiples non-caseating epithelioid granulomata (Fig. 1). A Kveim test was not performed on patient 3, and wass negative in the others.

\section{Discussion}

Multiple epithelioid granulomata are found if $3-10 \%$ of liver biopsies (Guckian and Perry, 1966) The aetiology is seldom obvious on histologica grounds alone but may eventually be ascertained i 


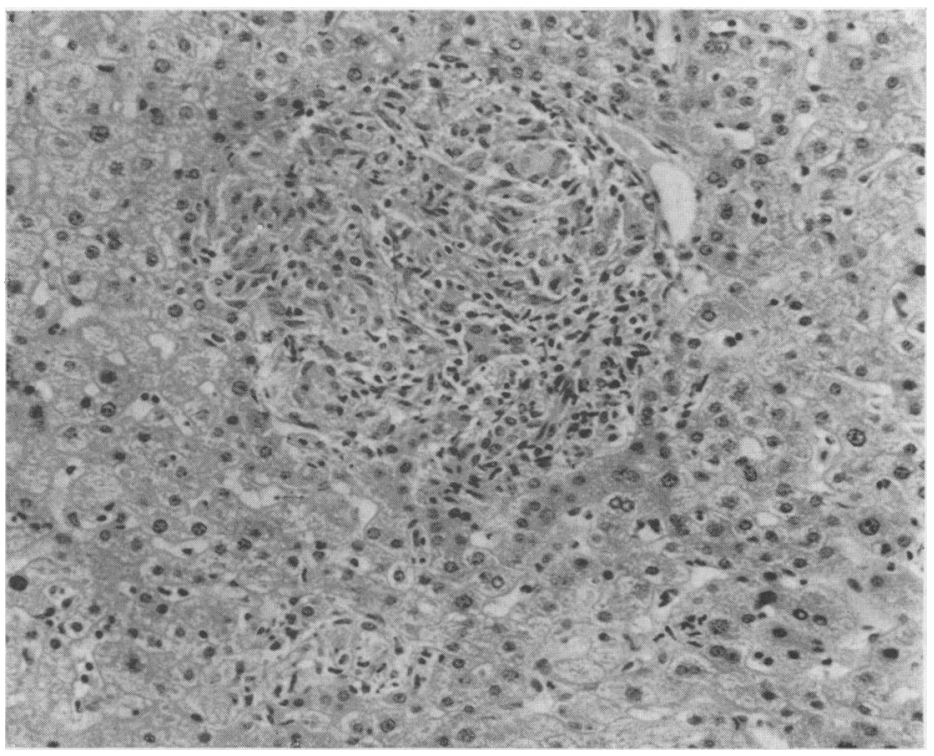

FIG. 1. Liver biopsy (Patient 2) showing a well circumscribed non-caseating giant cell granuloma $(\mathrm{HE}, \times 200)$.

most patients (Klatskin, 1977). The commonest causes are sarcoidosis, tuberculosis and primary biliary cirrhosis but there are many others. After extensive investigation no cause was found in the 4 patients described in this paper.

These patients all presented with pain, mainly in the right hypochondrium. It was frequently aggravated by food, and vomiting was common. Antacids were ineffective and simple analgesia gave the best relief. There was no associated arthralgia, fever, pruritus or bowel disturbance.

Neville et al. (1975) found an elevated alkaline phosphatase in $64 \%$ of their patients with idiopathic granulomatous hepatitis, and an elevated SGOT in $55 \%$. These enzymes were increased in $50 \%$ of the patients described by Guckian and Perry (1966). In the present patients, alkaline phosphatase and SGOT were raised in 2 cases (nos. 2 and 4), with an elevated $\gamma$-GT in 3 (nos 2, 3 and 4).

Many reviews do not mention abdominal pain as a feature of granulomatous hepatitis (Terplan, 1971; Fitzgerald, Fitzgerald and Towers, 1971; Israel and Goldstein, 1973; Klatskin, 1977). However, Neville et al. (1975) comment that $18 \%$ of their patients with liver granulomata had abdominal pain, more commonly $(50 \%)$ in those with no cause found. Similarly Simon and Wolff (1973) mention that 6 out of 13 patients with pyrexia and granulomatous hepatitis had abdominal pain, predominantly affecting the right upper quadrant. Guckian and Perry (1966) in an analysis of cases noted abdominal pain in $33 \%$ of patients with granulomatous hepatitis due to sarcoidosis or tuberculosis, but in only $8 \%$ with the idiopathic variety-on later investigations of these, Guckian and Perry (1968) often found a cause.

The 4 patients described presented initially with severe abdominal pain. The granulomatous hepatitis was only diagnosed after extensive investigation. Abdominal pain of uncertain aetiology is a common clinical problem and in some patients may be due to unrecognized granulomatous hepatitis.

\section{Acknowledgment}

We would like to thank Dr D. Davies for Fig. 1.

\section{References}

Fitzgerald, M.X., Fitzgerald, O. \& Towers, R.P. (1971) Granulomatous hepatitis of obscure aetiology. Quarterly Journal of Medicine, 40, 371.

Guckian, J.C. \& Perry, J.E. (1966) Granulomatous hepatitis. An analysis of 63 cases and review of the literature. Annals of Internal Medicine, 65, 1081.

Guckian, J.C. \& Perry, J.E. (1968) Granulomatous hepatitis of unknown etiology. American Journal of Medicine, 44, 207.

ISRAEL, H.L. \& GoldSTEIN, R.A. (1973) Hepatic granulomatosis and sarcoidosis. Annals of Internal Medicine, 79, 669.

KLATSKIN, G. (1977) Hepatic granulomata: problems in interpretation. Mount Sinai Journal of Medicine, 44, 798.

Neville, E., Piyasena, K.H.G. \& James, D.G. (1975) Granulomas of the liver. Postgraduate Medical Journal, 51, 361 .

Simon, H.B. \& WolfF, S.M. (1973) Granulomatous hepatitis and prolonged fever of unknown origin: A study of 13 patients. Medicine, 52, 1 .

Terplan, M. (1971) Hepatic granulomas of unknown cause presenting with fever. American Journal of Gastroenterology, 85, 43. 